\title{
Correction to: Biomechanical Influence of Treatment Table Axis Location on Axial Rotation of Lumbar Spine
}

\author{
Yoon Hyuk Kim ${ }^{1} \cdot$ Kyungsoo $\mathrm{Kim}^{2} \cdot$ Won Man Park ${ }^{3}$
}

Published online: 26 May 2021

(c) Korean Society for Precision Engineering 2021

\section{Correction to: \\ International Journal of Precision Engineering and Manufacturing (2021) 22:889-897 \\ https://doi.org/10.1007/s12541-021-00499-w}

Due to an unfortunate oversight the acknowledgment section should read:

Acknowledgements This research was supported by Basic Science Research Program through the National Research Foundation of Korea (NRF) funded by the Ministry of Education (No. NRF2017R1D1A1B03034668). The authors would like to thank Mr. Jae Lak Yang at HANMED CO., LTD to provide information about spinal mobilization and treatment table.
Publisher's Note Springer Nature remains neutral with regard to jurisdictional claims in published maps and institutional affiliations.

The original article can be found online at https://doi.org/10.1007/ s12541-021-00499-w.

Won Man Park

muhaguy@gmail.com

1 Department of Mechanical Engineering, and Integrated Education Institute for Frontier Science \& Technology, Kyung Hee University, Yongin, Korea

2 Department of Applied Mathematics, Kyung Hee University, Yongin, Korea

3 Elsoltec, \#1401-2, BLDG A, Jungbu-daero, Giheung-gu, Yongin 17095, Korea 